\title{
AGENTES LOCALES Y PROYECTOS TRANSFRONTERIZOS EN EL EJE TRANSPIRENAICO BARCELONA-TOULOUSE
}

\author{
Xavier Oliveras González
}

Departamento de Estudios Urbanos y Medio Ambiente, Colegio de la Frontera Norte, 87499 Matamoros, Tamaulipas, México

xoliveras@colef.mx

Antoni Durà Guimerà

Departament de Geografia, Universitat Autònoma de Barcelona, 08193 Bellaterra (Cerdanyola del Vallès)

antoni.dura@uab.cat

\begin{abstract}
Resumen: Los agentes públicos locales, por ser la administración territorial más próxima, detectan necesidades o conflictos, pero pueden no tener las competencias administrativas para gestionarlos. En el artículo se recoge la propuesta y rechazo de proyectos territoriales a administraciones superiores en un contexto transfronterizo. El análisis se centra en el ámbito territorial del eje transpirenaico Barcelona-Toulouse (frontera España-Andorra-Francia), y en dos contextos político-administrativos diferentes, anterior y posterior a la regulación jurídica de la cooperación transfronteriza. En concreto se analizan seis casos, en los ámbitos de las infraestructuras de transporte (la línea ferroviaria Barcelona-Toulouse, y la carretera E-09), la sanidad (el Hospital Transfronterizo de Cerdanya) y la gestión del agua (trasvases de aguas y las depuradoras de la cuenca alta del Segre). Se avalúa el rol de los agentes así como el de los proyectos en la construcción regional transfronteriza.
\end{abstract}

Palabras clave: cooperación transfronteriza, frontera España-Francia, agentes locales, infraestructuras de transporte, sanidad, gestión del agua.

Abstract: Local public actors, as the nearest territorial administration, can detect needs and conflicts, but may not have the administrative compe-

Recibido: 7-05-13. Aceptado: 3-12-13. 
tences for managing them. The paper shows territorial projects proposal and rejection to higher administrations in a cross-border context. The analysis focuses on the Transpyrenean axis of Barcelona-Toulouse (SpainAndorra-France border), and in two different political and administrative contexts: before and after the juridical regulation of cross-border cooperation. Six examples are analysed, that are related to transport infrastructure (the Barcelona-Toulouse railway line, and the E-09 road), healthcare (the Cross-Border Hospital of Cerdanya) and water management (diversions of water and water treatment plants in upper Segre basin). It is evaluated the contribution of the actors and projects to cross-border regional construction.

Key words: cross-border cooperation, Spain-France border, local actors, transport infrastructures, healthcare, water management.

\section{Introducción}

¿Quién construye las regiones transfronterizas? O, dicho de otro modo, ¿̨cuáles son los agentes territoriales implicados en la integración de espacios fronterizos? y ¿mediante qué procesos se implican? Como expresan Trillo y Lois (2011, p. 116) una región transfronteriza es el resultado de la interacción entre un espacio compartido a ambos lados de la frontera estatal y las acciones llevadas a cabo por actores implicados en dicho contexto. Las aportaciones teóricas y empíricas sobre esta cuestión (Paasi, 1996; Perkmann, 2003; Ramírez, 2005; Hinfray, 2007; Oliveras, Durà y Perkmann, 2010; Breugnot 2012; entre otros), han mostrado ampliamente que se trata de un proceso eminentemente dirigido y liderado por los agentes locales y regionales. Ello no excluye la intervención de las instancias estatales y supraestatales, cuyas acciones, por acción u omisión, influyen directamente. La misma definición continúa señalando que la región transfronteriza se dota de contenido a través de procesos de construcción social mediante proyectos, discursos y representaciones asociados a ella (Trillo y Lois 2011, p. 116). En este punto la cooperación transfronteriza, es decir, la colaboración en menor o mayor grado institucionalizada entre agentes públicos (autoridades, organismos y entes subestatales) y/o agentes privados (cámaras de comercio, agencias de desarrollo, asociaciones ciudadanas, etc.), colindantes de dos o más estados, y orientada a la coordinación de políticas y acciones, constituye una de las estrategias para la construcción de dichas regiones. El éxito de la construcción regional mediante la cooperación se apoya en la mejora de la planificación y gestión territoriales, de la dotación de infraestructuras y servicios públicos, de la calidad de vida de sus habitantes, etc.; sirvan de ejemplo las experiencias, en muchos casos pioneras y de larga trayectoria, de las regiones metropolitanas en el espacio fronterizo entre Francia, Suiza, Alemania, Luxemburgo y Bélgica (SchneiderSliwa, 2008; Sohn, 2010). 
Sobre la cooperación en proyectos territoriales, la literatura académica se ha centrado casi exclusivamente en la concertación y realización de aquellos sobre los cuales los agentes locales y regionales poseen competencias. Esta limitación viene determinada por el hecho que las regulaciones europea y nacionales de la cooperación transfronteriza, con todas las posibilidades y oportunidades que ofrece, fijan que se ejercerá en el marco de las competencias de las comunidades o autoridades territoriales, tal como esas competencias se definen en el derecho interno de cada país (Convenio-marco europeo sobre cooperación transfronteriza entre comunidades o autoridades territoriales, Art. 2.1) ${ }^{1}$. En síntesis, la cooperación regulada sólo es posible en aquellos ámbitos sobre los que dichos gobiernos detentan competencias administrativas ${ }^{2}$, y ello sin tener en cuenta otros obstáculos legales y prácticos que se imponen. En esta dirección, el presente estudio tiene por objetivo identificar el proceso de construcción regional en un marco de ausencia de competencias y de limitación de la cooperación transfronteriza regulada. Es necesario indicar que la distribución competencial en diferentes niveles administrativos puede conllevar la no coincidencia entre el ente que detecta una necesidad y el que detenta la capacidad para darle respuesta. Se trata la mayor parte de las veces de la administración local en relación a la regional o ambas en relación a la estatal. Como se ha podido comprobar, y se expondrá más adelante, frente a esto los agentes locales y regionales adoptan dos estrategias básicas: una, proponer y reivindicar a los niveles superiores proyectos territoriales de interés local y regional, y, en otras circunstancias, oponerse al desarrollo de proyectos promovidos por los niveles estatal en los espacios locales.

La demanda de proyectos territoriales es en los espacios fronterizos más acuciante, en tanto que muchas veces constituyen las periferias de los estados. Las regiones periféricas y/o fronterizas, y tanto más si coindicen con áreas rurales y de montaña, suelen ser poco prioritarias para los gobiernos centrales, y así a la vez lo perciben las comunidades locales. Justamente esta es una de las principales denuncias de las asociaciones regionales de escala europea, de las que destacan por ello la Asociación de Regiones Fronterizas de Europa (ARFE) y la Conferencia de Regiones Periféricas y Marítimas de Europa (CRPM). Además de reivindicar mayores inversiones por parte de los gobiernos estatales, promueven la cooperación transfronteriza como uno de los mecanismos para solventar los déficits relativos al desarrollo regional. Con este propósito, entre otras razones, la Unión Europea creó los fondos INTERREG.

En el contexto de la frontera España-Francia-Andorra, se ha analizado la articulación de alianzas y redes transfronterizas de agentes locales para la proposición y reivindicación u oposición de proyectos territoriales. El estudio se centra en el espacio

1. Boletín Oficial del Estado, 16/10/1990, núm. 248, p. 30271.

2. Como indica Marcou (2006), a nivel jurídico se debería distinguir entre "potestad" y "competencia": mientras la primera supone una capacidad y poder de actuación otorgadas por los textos constitucionales o leyes de rango inferior, la segunda es el objeto al que se aplica. La combinación de ambas es lo que determina el grado de autonomía. Para los objetivos de este estudio se utilizará genéricamente el término "competencia". 
transpirenaico que une Barcelona y Toulouse por los valles fluviales del Llobregat, Segre y Ariège, en el sector oriental de la línea fronteriza (figura 1). Sobre este eje se apoya, junto dos más, el triángulo formado por Catalunya (España), Languedoc-Roussillon y Midi-Pyrénées (Francia) y Andorra, y a lo largo del cual se han establecido varias relaciones institucionales transfronterizas, principalmente Barcelona, Terrassa, Manresa, Berga, Puigcerdà, Andorra la Vella, Ax-les-Thermes, Foix, Pamiers y Toulousse. Por sus particularidades sobresale además la Cerdanya, comarca de montaña dividida entre ambos estados por el Tratado de los Pirineos de 1659 y el Tratado de Llivia de 1660, ubicada en la periferia de ambos y fronteriza además con Andorra. Desde los años 1980, se han desarrollado allí varias acciones conjuntas (Oliveras, 2013).

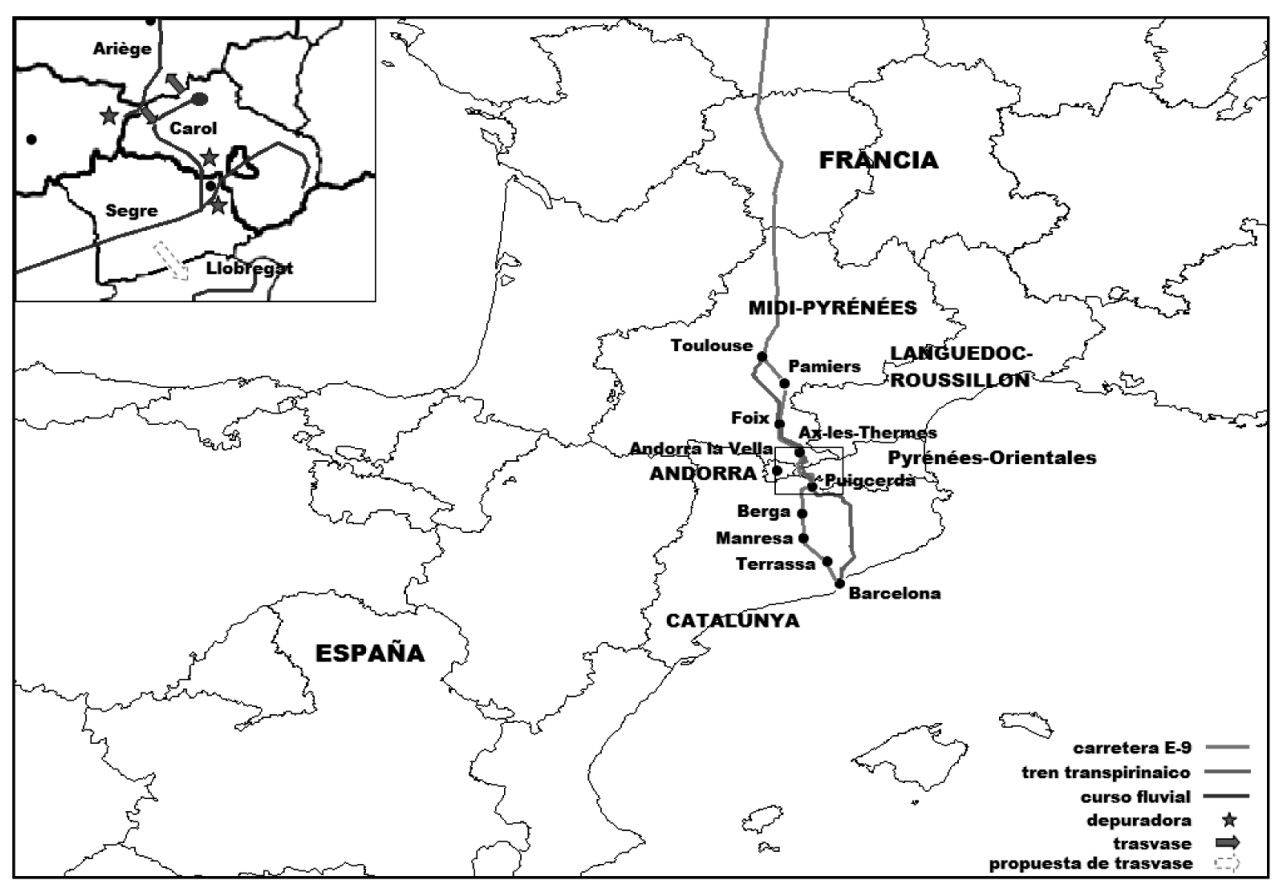

Figura 1. El eje transpirenaico Barcelona-Toulouse.

Fuente: Elaboración propia.

Se examinan tres ámbitos sobre los que las administraciones locales tienen escasas o nulas competencias: infraestructuras de transporte, equipamientos sanitarios y gestión del agua. En todos los casos se trata de infraestructuras, equipamientos y servicios que responden a problemas y/o necesidades compartidas en espacios geográficos contiguos situados a ambos lados de la frontera. La ARFE y la CRPM ubican estos ámbitos entre los retos en y para las áreas fronterizas, periféricas y/o de montaña, y la UE los 
ha incluido como prioritarios para la cooperación transfronteriza. Los casos concretos estudiados reflejan la integración de dicho eje territorial, especialmente en lo que se refiere a la expansión hacia el Pirineo de los procesos metropolitanos de Barcelona y, en menor medida, de Toulouse (Mancebo, 1999; Vivas, 2004). Así, mientras a nivel estatal la Cerdanya continúa siendo un espacio fronterizo y periférico, en la escala regional deja de serlo para convertirse en un nexo de unión entre las regiones metropolitanas de ambas ciudades. En esta dirección, la consecución de los proyectos territoriales reivindicados permite incrementar la integración transfronteriza, especialmente en un espacio más próximo a la frontera como es la Cerdanya. Asimismo, e independientemente de la ejecución o no de los proyectos, las alianzas transfronterizas reflejan y a la vez contribuyen una construcción regional a nivel institucional y simbólico. Desde otra perspectiva, Sempere (2011) y Cohen et al. (2011) han analizado una cuestión similar, tomando el caso de la oposición ciudadana a un proyecto transfronterizo impulsado por los gobiernos francés y español relativo a la distribución de energía, la línea de Muy Alta Tensión (MAT) entre Baixas (Pyrénées-Orientales) y Sentmenat (Barcelona). Por último, el análisis se ha realizado a partir del seguimiento de las acciones de los agentes locales en los medios de comunicación locales y regionales (principalmente Regió 7, La Vanguardia y Ceretania, del lado español, La Clau, L'independant y Midi Libre, del francés, y El Periòdic d'Andorra, del andorrano), y de entrevistas y valoraciones cualitativas, cuando ha sido posible, con agentes locales y regionales representativos.

\section{Regulación y experiencia de la cooperación transfronteriza en la frontera España-Francia-Andorra}

La moderna cooperación transfronteriza en Europa se inicia en las décadas de 1950 y 1960 (Perkmann, 2003). Desde las fronteras de la Europa occidental y nórdica el fenómeno se difunde lenta pero progresivamente hasta cubrir actualmente la práctica totalidad de fronteras del continente. La expansión y consolidación de la cooperación se explica por un creciente rol de los agentes regionales y locales -ejemplificado en la influencia ejercida por la ARFE y la CRPM, creadas en 1971 y 1973 respectivamente-, junto con el apoyo jurídico que le otorgó el Consejo de Europa (CdE) desde los años 1980 y el apoyo financiero de la Unión Europea (UE) mediante el programa INTERREG -actualmente Cooperación Territorial Europea-, creado en 1989. En estos últimos treinta años se ha desarrollado un corpus legal que, frente a una inicial situación ambigua, dota a las entidades subestatales de la capacidad de colaborar con entidades colindantes de otros estados, siempre y cuando se respeten los acuerdos internacionales de los estados respectivos y de acuerdo a sus competencias administrativas. En el espacio fronterizo de España y Francia y, en menor medida, Andorra se han establecido varios organismos y proyectos de cooperación, desde la escala regional hasta la local. En la actualidad el fenómeno tiene ya una cierta importancia, por su densidad, diversidad y perdurabilidad, como se des- 
prende de los trabajos de Fernández de Casadavante (1989 y 1990), Fernández y Peralta (1994), Galan (1994), Morata (1995), Muñoz (1995), Tambou (2000), Arbaiza (2006), Harguindéguy (2007), Silván (2008) o Durà (2012), entre otros.

\subsection{Las bases jurídicas de la cooperación transfronteriza}

Lejos de los temores de los Estados europeos suscitados inicialmente por la cooperación transfronteriza subestatal (principalmente la invasión de su soberanía e interés nacionales), el actual fenómeno está en menor o mayor grado posibilitado y reglamentado por estos. Hasta la década de 1980 el nivel de oposición estatal fue tal que incluso la ARFE se vio obligada a remarcar, en la Carta europea de las regiones fronterizas y transfronterizas (1981), que la disposición de los habitantes, las comunidades y las regiones de buscar conjuntamente soluciones transfronterizas no se encuentra dirigida por la intención de cambiar [las] fronteras o eliminar la soberanía de los estados. [...]. El objetivo [...] no es por tanto, la creación de un nuevo nivel administrativo, sino el desarrollo de estructuras de cooperación, procedimientos e instrumentos que posibiliten y faciliten la reducción de obstáculos y factores de separación, asi como la superación de la frontera. Desde este punto de vista, su diseño no difiere mucho de otras modalidades de cooperación territorial intraestatal, aunque sí puede serlo a nivel metageográfico, simbólico y geopolítico. La "aceptación" de la cooperación subestatal se produjo en el marco de su regulación jurídica a nivel supraestatal, básicamente del CdE y la UE, y estatales, con las cuales quedaba definida dentro de unos condicionantes formales. Justamente, es a partir de la entrada en funcionamiento de estas regulaciones cuando la cooperación se intensifica y expande territorialmente en mayor grado: a día de hoy no hay ningún gobierno regional fronterizo de la UE que no participe en al menos un proyecto transfronterizo (Oliveras, Durà y Perkmann, 2010). Para entender su desarrollo en el espacio fronterizo de los Pirineos deben tenerse en cuenta tres fuentes jurídicas.

En primer lugar, en 1980 el CdE aprobó la que es la primera regulación jurídica, el Convenio-marco europeo de cooperación transfronteriza entre autoridades y comunidades territoriales, más conocido por Convenio-marco de Madrid, y ampliado posteriormente con tres protocolos adicionales (en 1995, 1998 y 2009). España y Francia lo ratificaron en 1990 y 1984, seguido en 1995 de la rúbrica de un acuerdo bilateral, el Tratado relativo a la cooperación transfronteriza entre colectividades territoriales (o Tratado de Bayona) ${ }^{3}$, que entró en vigor dos años después. Recientemente, en 2012, Andorra se adhirió al tratado $^{4}$, después de la aceptación por parte de ambos estados de ampliarlo y a pesar de que Andorra todavía no había firmado ni ratificado el Convenio-marco de Madrid. Por este tratado se autoriza a las respectivas entidades subestatales (municipios, departamentos

\footnotetext{
3. Boletín Oficial del Estado, 10/03/1997, núm. 59, p. 7789.

4. Boletín Oficial del Estado, 20/11/2012, núm. 279, p. 80495.
} 
y provincias, y regiones, y sus agrupaciones) fronterizas (figura 2) a establecer convenios de cooperación y constituir organismos (con o sin personalidad jurídica de derecho público), con los objetivos de crear y gestionar equipamientos y servicios públicos, estudiar y coordinar decisiones en los dominios de interés común y formular propuestas de cooperación. De acuerdo a las disposiciones del Tratado de Bayona, ambos estados han firmado otros acuerdos bilaterales sectoriales donde se contempla la cooperación subestatal, tales como el Acuerdo de Toulouse de 2006 sobre cuencas hidrográficas transfronterizas o, muy especialmente, el Acuerdo marco sobre cooperación sanitaria transfronteriza de 2008. Con este último, por ejemplo, se desea mejorar el acceso a la asistencia sanitaria, garantizar su continuidad entre las poblaciones de la zona fronteriza y simplificar los procedimientos administrativos y financieros.

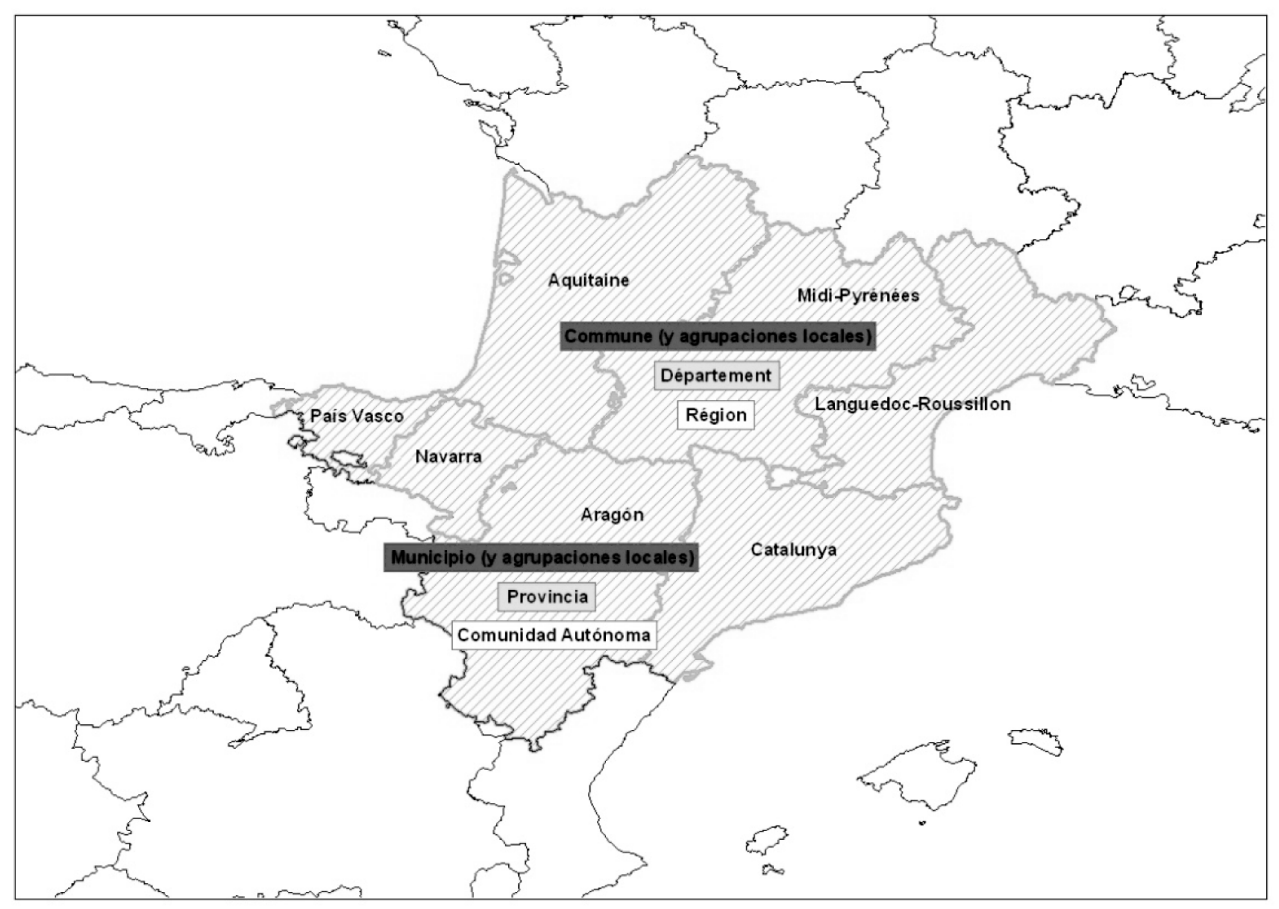

Figura 2. Área y niveles territoriales de aplicación del Tratado de Bayona (1995).

Fuente: Elaboración propia.

La UE, por su parte, añadió en 2006 su propia regulación jurídica, el Reglamento sobre las Agrupaciones Europeas de Cooperación Territorial (AECT) (Embid y Fernández de Casadevante, 2008), aunque con anterioridad se había extendido el uso de otro reglamento, el de las Agrupaciones Económicas de Interés Europeo (AEIE), como re- 
gulación de facto. El reglamento de las AECT no aporta grandes novedades de fondo, aunque supera algunas de las limitaciones del Convenio-marco de Madrid en relación a la constitución de organismos transfronterizos. España y Francia acordaron en 2009 el procedimiento de participación de sus entidades subestatales.

En tercer y último lugar, la descentralización de España y Francia, desde fines de los años 1970 y a lo largo de los 1980, se acompañó de la concesión de autonomía política y financiera a sus entidades subestatales. A pesar de la coincidencia temporal, debe señalarse la asimetría en la arquitectura institucional de ambos, marcada sobre todo por el poder legislativo y el notable grado de competencias de las Comunidades Autónomas en contraste con el escaso poder de las regiones francesas. A pesar de las diferencias, esta autonomía posibilita el establecimiento de acuerdos de cooperación transfronteriza y el ejercicio de las relaciones exteriores. Esta capacidad está sujeta a los acuerdos internacionales y bilaterales mencionados y a las legislaciones específicas de ambos estados. Francia ha sido el estado que en mayor grado ha procedido a su reglamentación, en el Code Général des Collectivités Territoriales (de $1992^{5}$ y ampliado en 1995, 1999 y 2004). En el estado español, por su parte, se aprobó en 1997 un primer reglamento ${ }^{6}$, que se complementa con las modificaciones de 2003 añadidas a la Ley Reguladora de las Bases Locales de 19857. Ambas legislaciones obligan a una comunicación previa a la administración central, a una restricción dentro de los límites competenciales y al respeto a los compromisos internacionales del estado. En el caso español, parece que la nueva ley de Acción y Servicio Exterior viene a reforzar estos condicionantes, al señalar que se someterán a informe del Gobierno los acuerdos que las Administraciones autonómicas o locales celebren con organismos extranjeros o internacionales para verificar que no desbordan sus competencias. ${ }^{8}$. Estas legislaciones definen, por último, la personalidad jurídica de los organismos de cooperación (Consorcios, y Groupements d'Intérêt Public, Sociétés d'Économie Mixte Locales y Districts Européens).

\subsection{La trayectoria de los agentes territoriales en la cooperación transfronteriza}

En la frontera hispano-francesa la cooperación transfronteriza empieza a desarrollarse a partir de los años 1980, con el restablecimiento del régimen democrático en el estado español y su plena integración en el marco institucional europeo. El fenómeno no partió completamente desde cero, ya que se mantenían a nivel local modalidades

5. Loi d'orientation 92-125 relative à l'administration territoriale de la République, de 6 de febrero de 1992.

6. Real Decreto 1317/1997, sobre comunicación previa a la Administración General del Estado y publicación oficial de los convenios de cooperación transfronteriza de Comunidades Autónomas y Entidades Locales con Entidades Territoriales extranjeras, de 1 de agosto de 1997.

7. Ley 57/2003, de medidas para la modernización del gobierno local, de 16 de desembre.

8. "Exteriores tutelará la actuación de las autonomías en el extranjero", El País, 27/01/2013. 
anteriores que se le asemejan, con lo que existía un cierto know-how. Una encuesta realizada en 1982 a 163 autoridades locales de ambos lados de la frontera mostraba que se daban algunas relaciones institucionales más o menos formales, más o menos sistemáticas y en general de poca intensidad (Bernad, 1984; Fernández y Peralta, 1994). Se trataba en algunos casos de reminiscencias de los antiguos tratados de paz y de facerías, como el Tributo de las Tres Vacas, que reúne, desde 1375 como mínimo, los vecinos de los valles de Baretous (Pyrénées Atlantiques) y de Roncal (Navarra); de hermanamientos entre municipios, tales como Lleida y Foix (Ariège), Barbastro (Huesca) y Saint Gaudens (Haute Garonne) o Vielha (Lleida) y Baziège (Haute Garonne), establecidos en 1962, 1963 y 1970 respectivamente; y de comisiones locales creadas bajo el paraguas de la Comisión Internacional de los Pirineos (CIP), como es el caso de la Comisión Internacional de Administración del canal de Puigcerdà creada en 1868 y que reúne los gobiernos locales y las comunidades de regantes de Puigcerdà (Girona) y Enveitg y Latour-de-Carol (Pyrénées Orientales).

En la década de 1970 el CdE promovió a nivel europeo la creación de varias comunidades de trabajo, entre las cuales una aquitano-cantábrica. A pesar de que nunca llegó a crearse, los esfuerzos del CdE condujeron a la celebración en 1982 de la Conferencia de las Regiones Pirenaicas y la aprobación de la Declaración de Jaca, y al año siguiente a la fundación de la Comunidad de Trabajo de los Pirineos (CTP), con lo que se da comienzo realmente a dicho fenómeno. Este organismo transfronterizo está integrado por Aragón, Catalunya, Navarra y Euskadi, en España, Languedoc-Roussillon, Midi-Pyrénées y Aquitaine, en Francia, y Andorra. Posteriormente, en 2005, ya en el marco del Tratado de Bayona, adoptó la figura jurídica de consorcio, que le suponía un mayor reconocimiento hispanofrancés y lo hacía más operativo (como contratar personal y servicios). Esto posibilitó, además, que la CTP se convirtiera en 2007 en la autoridad de gestión del Programa Operativo España-Francia-Andorra (POCTEFA), dependiente del programa de la UE Cooperación Territorial Europea.

En el sector oriental de la frontera en concreto, en el año 1980 se establecieron los primeros contactos entre los gobiernos regionales de Catalunya, Languedoc-Roussillon y Midi-Pyrénées, así como entre los ayuntamientos de las respectivas capitales, que se fueron intensificando a lo largo de aquella década. Desde un primer momento se plasmó la voluntad de asociarse para la gestión de proyectos de interés mutuo, especialmente en los ámbitos económico, social y cultural. El proceso culminó con la creación en 1989 de una Euroregión constituida por los tres gobiernos regionales, y en 1990 de la Red de Ciudades C-6, integrada por los gobiernos locales de Barcelona, Palma, Valencia, Zaragoza, Montpellier y Toulouse. La experiencia de la Euroregión quedaría poco después interrumpida por razones puramente políticas, hasta que en 2003 se replanteó de nuevo. Finalmente en 2004 se creó la Euroregión Pirineos Mediterráneo (EPM), en la que se integraron, además de aquellas tres regiones, Aragón y Balears, aunque posteriormente el gobierno aragonés se retiró. La EPM se convirtió en 2009 en uno de los primeros organismos transfronterizos de Europa en adaptarse al Reglamento de las AECT. 
Paralelamente se han desarrollado también un conjunto de iniciativas de ámbito más local, los espacios de actuación de las cuales se solapan en ocasiones. Además de los varios proyectos cofinanciados mediante los programas INTERREG, al igual que en la escala regional se han formado otros tantos organismos transfronterizos. Se puede hacer referencia al Eurodistrito del Espacio Catalán Transfronterizo, que agrupa desde 2007 a varios miembros, sobre todo gobiernos municipales y supramunicipales, de la provincia de Girona y del departamento de Pyrénées Orientales. En una escala comarcal, en la década de los 1990 estuvo en activo la Asociación de Muncipios de la Cerdanya (AMC), que agrupaba la casi totalidad de los municipios de la Cerdanya española y francesa, pero que, como otras primeras iniciativas, fracasó por la frustración resultante de unas expectativas demasiado altas. Partiendo de aquella experiencia se constituyó en 2012 la AECT Pirineos-Cerdanya, integrada por el Consell Comarcal de la Cerdanya, en España, y la Communauté de Communes Pyrénées-Cerdagne, en Francia, y con unos objetivos más acordes a les posibilidades financieras y técnicas reales.

Desde un punto de vista de la construcción regional, en cada una de estas iniciativas han prevalecido diferentes aspectos. En algunos casos se ha priorizado la integración institucional, como en la EPM y el Eurodistrito, mientras que en otros se ha tratado de una colaboración más a nivel técnico, como en la CTP. En otras, sobre todo aquellas de escala local, se ha enfatizado en mayor grado la concertación de las políticas, objetivos y estrategias de desarrollo territorial (planificación y gestión de espacios, infraestructuras y equipamientos, y promoción territorial).

\section{Ejemplos de reivindicaciones transfronterizas de proyectos territoriales}

Comúnmente el objetivo de la cooperación transfronteriza es el desarrollo de proyectos territoriales, pero en ocasiones sirve para promoverlos u oponerse a ellos. Se da sobre todo en aquellas situaciones en que los agentes locales y/o regionales no poseen -total o parcialmente y en ambos lados de la frontera, o en uno de ellos- las competencias administrativas para implantarlos. En este sentido, las administraciones locales y regionales utilizan la cooperación como un mecanismo para el ejercicio de presión frente a las administraciones de rango superior. Considerando el marco legislativo y los presupuestos anteriormente enunciados, a continuación se exponen algunos ejemplos de la reclamación local de proyectos territoriales a las administraciones superiores de España, Francia y Andorra. Cómo ya se ha avanzado, los casos analizados corresponden a tres ámbitos (infraestructuras de transporte, equipamientos sanitarios y gestión del agua), de los que se han seleccionado un total de seis experiencias. La selección cubre los dos tipos de reivindicación referidos (proposición y rechazo), y se sitúan cronológicamente tanto antes como después de la regulación de la cooperación transfronteriza (figura 3). Asimismo, se completa con un caso que se extiende en las dos temporalidades 
y otro donde los agentes de un lado de la frontera rechazan sumarse a los del otro. En el lado español, las competencias dependen del Estado y la Generalitat de Catalunya, mientras que en el francés lo son mayoritariamente del Estado y, en menor medida, de los consejos regionales (región) y generales (departamento) e, incluso en alguna ocasión, de los municipios (Marcou, 2006; Navarro, 2010; Verpeaux y Rimbault, 2011).

\begin{tabular}{|c|c|c|c|}
\hline & \multicolumn{2}{|c|}{ Tipo de reivindicación } \\
\hline & & Proposición & Rechazo \\
\hline \multirow[b]{2}{*}{$\begin{array}{l}\text { Regulación } \\
\text { de la } \\
\text { cooperación } \\
\text { transfronteriza }\end{array}$} & Anterior & Ferrocarril transpirenaico & Trasvase del Carol al Ariège \\
\hline & Posterior & $\begin{array}{l}\text { Ferrocarril transpirenaico } \\
\text { Vía E-09 } \\
\text { Hospital de Cerdanya } \\
\text { Depuradoras en la cuenca del Segre }\end{array}$ & Trasvase del Segre al Llobregat \\
\hline
\end{tabular}

Figura 3. Proyectos transfronterizos seleccionados.

Fuente: Elaboración propia.

\subsection{Infraestructuras de transporte}

Desde los inicios de la cooperación transfronteriza, pero también antes, las infraestructuras de transporte transpirenaico ha sido uno de los principales ámbitos de proposición y reivindicación (Giménez, 2012). Muchas de las propuestas hispano-francesas se han articulado en y desde la CTP y las Euroregiones, sin excluir los organismos locales. En general, las propuestas se sustentan sobre tres pilares: la permeabilización de los Pirineos, para mejorar las comunicaciones terrestres entre las dos vertientes de la cordillera por otros corredores que no sean los extremos litorales; el desarrollo local y regional, que podría inducir la existencia de la infraestructura, especialmente en lo que se refiere al crecimiento de las actividades turísticas, residenciales (construcción) y logísticas (comerciales); y, por último, la cooperación interregional, derivado de un posible acercamiento simbólico e institucional entre ambos lados de la frontera. En general los agentes locales han generado unas expectativas muy altas en relación a las condiciones sociodemográficas y socioeconómicas (tanto del área pirenaica como de las regiones metropolitanas de Barcelona y Toulouse) y a los modelos de movilidad. Asimismo, los proyectos no se han realizado en su totalidad, ya sea por diferentes prioridades políticas de las administraciones superiores, ya sea por su viabilidad económica. Sea como fuere, las expectativas han tendido a no cumplirse, con alguna excepción, como la apertura del túnel del Cadí y el desarrollo local en la Cerdanya (Vivas, 2004).

\subsubsection{La vía E-09 (Barcelona-Toulouse-París)}

A iniciativa de la Federación Internacional de Carreteras y la Comisión Económica para Europa de las Naciones Unidas, se firmó en 1975, en Ginebra, el Acuerdo europeo sobre 
las principales arterias de tráfico internacional que, entre otros aspectos, inauguraba la Red de Enlaces por Carretera de Interés Comunitario (más conocida como Red E). Por este acuerdo, los estados firmantes, entre los cuales España y Francia, se comprometían a la construcción y desarrollo de una malla cuadriculada de vías rápidas de importancia internacional, de orientación norte-sur y oeste-este, y adaptadas a los respectivos planes estatales. Por la frontera hispano-francesa se previó un paso por el Pirineo oriental de Clase A, la vía E-09, sobre la que se propusieron dos itinerarios que diferían en su trazado, quedando finalmente fijado en 1984. El recorrido une París, Orléans, Limoges, Toulouse, Manresa, Terrassa y Barcelona, cruzando el Pirineo por la Cerdanya. Como parte del Acuerdo de Ginebra, España (y Catalunya) y Francia lo introdujeron en los respectivos planes directores de infraestructuras de transporte, reconociendo su vocación transpirenaica y europea y con la consideración de vía de gran capacidad.

El primer reto, en las décadas de 1980 y 1990, fue la perforación de túneles para salvar la cordillera pirenaica. Los túneles imprescindibles, según Prat (1994), eran el del Cadí (España) y el de Puymorens (Francia), en los extremos sur y norte de la Cerdanya e inaugurados en 1984 y 1994 respectivamente. En el lado español, la entrada en funcionamiento del túnel del Cadí propició una intensa remodelación de la red viaria catalana, que mejoró notablemente la conexión entre la Región Metropolitana de Barcelona y el Pirineo. Su construcción fue un punto de inflexión, con importantes consecuencias para las dinámicas socioeconómicas de la comarca. En cambio, en el lado francés, desde la inauguración del túnel de Puymorens, las actuaciones y transformaciones no han sido tan importantes, aunque se mejoró la conexión entre el área metropolitana de Toulouse y el Pirineo. A pesar de todas las obras realizadas, hoy todavía queda pendiente la conversión en autovía del tramo entre Tarascon-sur-Ariège y Berga, de $120 \mathrm{Km}$, y que en los vigentes planes no está contemplado?. De hecho, la construcción de la E-09 se asemeja más a un conjunto de actuaciones aisladas, que además acumulan notables retrasos. Para los agentes locales, los retrasos y la inconclusión se traducen en una desventaja competitiva respecto a otras vías de comunicación, entre Barcelona y Toulouse y entre Andorra y Francia (sobre todo por lo que respecta a tiempo, riesgos y capacidad de transporte).

A lo largo de estos treinta años, varios municipios y redes transpirenaicas han reivindicado su realización completa. En primer lugar debe citarse la Comisión Transpirenaica de Poderes Locales, creada en 1984 después de una reunión de alcaldes de ambos lados de la frontera celebrada en la Seu d'Urgell ${ }^{10}$. Estuvo integrada por varios municipios de Catalunya, Andorra y Midi-Pyrénées situados a lo largo de este corredor, entre ellos los ayuntamientos de Barcelona, Andorra la Vella y Toulouse, además de Puigcerdà, la Seu

9. Pla d'infraestructures del transport de Catalunya 2006-2026, Catalunya; Plan de Infraestructuras, Transporte y Vivienda (PITVI) 2012-2024, España; y Schéma National des Infrastructures et des Transports (SNIT), que se prevé su aprobación en 2013 o 2014, Francia.

10. "Los alcaldes pirenaicos quieren vertebrar una región europea", La Vanguardia, 02/12/1984. 
d'Urgell, Ripoll, la Massana, Foix y Ax-les-Thermes. Su creación, después de la inauguración del túnel del Cadí y en el momento que se estaba discutiendo el trazado de la E-09, respondía al objetivo de presionar a los gobiernos español, francés y andorrano para que apostaran por aquella vía y, consiguientemente, se llevara a cabo cuanto antes la construcción del túnel de Puymorens y, en menor medida, los de Envalira y Toses. A esta petición se sumaron los gobiernos de Midi-Pyrénées, Pyrénées-Orientales y Catalunya, además de la Conferencia Permanente de las Cámaras de Comercio Pirenaicas de España y Francia (COPEF). Para respaldar la demanda, la Comisión encargó la realización de estudios sobre el trazado, la viabilidad económica y, sobre todo, los efectos en el desarrollo regional (se preveía un incremento de las relaciones comerciales y del turismo) en el ámbito de las áreas que conectaba y a escala europea. Además de la E-09, la asociación también apostó inicialmente por la conexión Barcelona-Toulouse por ferrocarril y avión, que pronto abandonó por suponer una competencia al transporte por carretera.

Paralelamente, en el seno de la Red C-6, de la que ya se ha hablado antes, se formó una Comisión de Transportes, presidida por el alcalde de Toulouse, con el fin de elaborar propuestas relativas a los principales ejes de conexión entre las capitales regionales y con el resto de Europa. En 1992 se presentaron sus conclusiones, en el Libro Blanco de las comunicaciones terrestres, donde establecía un conjunto de orientaciones en la política de infraestructuras viarias, señalando como uno de los principales proyectos el enlace transpirenaico E-09, que debería permitir la integración de la Europa septentrional y el Arco mediterráneo. Junto a éste, también se indicaban dos ejes más, la diagonal pirenaica entre Toulouse y Zaragoza (para el cual era imprescindible la construcción de un nuevo túnel, en un punto no especificado entre Vielha y Bielsa), y el enlace transpirenaico norte-sur por el túnel de Somport (Bordeux-Zaragoza-València) (figura 4). Las propuestas se elevaron a los gobiernos francés y español y a los regionales.

Una vez inaugurado el túnel de Puymorens en 1994, las actividades de la Comisión Transpirenaica de Poderes Locales y de la Comisión de Transportes de la Red C-6 disminuyeron lentamente, hasta la disolución de la primera en el año 2000 y de la desaparición de facto de la segunda un año después.

Hasta la redacción de los nuevos planes directores de infraestructuras de transporte de Francia y de Catalunya, de 2005 y 2006 respectivamente, no se produjo más que alguna reivindicación aislada y de poca intensidad. En ninguno de los dos se contempla el desdoblamiento hasta la frontera, al menos no antes de 2020, y solo la mejora de cortos tramos (Tarascon-Ax-les-Thermes, y Berga-Bagà). En este contexto, en 2008 varios municipios del departamento del Ariège -liderados por Ax-les-Thermes y agrupados desde 2009 en la Association Voie 9- y otros tantos de catalanes, encabezados por los ayuntamientos de Terrassa, Manresa, Berga y Puigcerdà, reclamaron una mayor prioridad. Los contactos iniciales partían de los previos hermanamientos entre las ciudades de Terrassa y Pamiers, y Berga y Tarascon-sur-Ariège, desde 1991 y 1994 respectivamente. Con el objeto de obtener el apoyo del Gobierno de Andorra, y que éste 


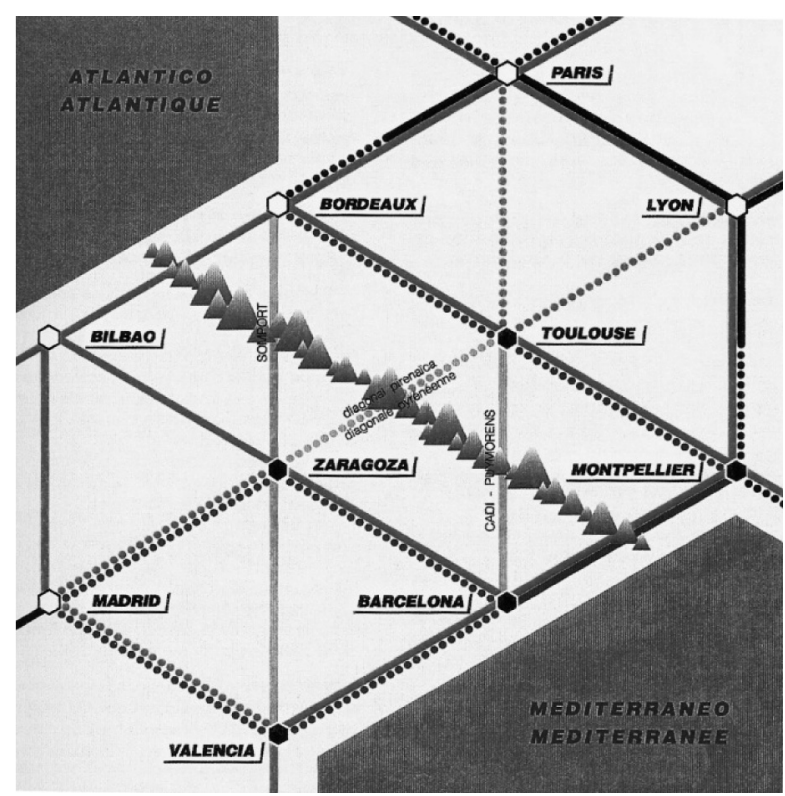

Figura 4. Las orientaciones de la Red C-6 (1992).

Fuente: Red de Ciudades C-6 (1992).

a su vez presionara a los gobiernos francés y catalán, en 2010 se celebró un encuentro en Andorra la Vella. Asistieron y/o se adhirieron un total de 92 municipios, 46 de Catalunya, 7 de Andorra -todos- y 39 de Midi-Pyrénées, y finalizó con la redacción y firma de la Declaración de Andorra para el eje estratégico de la E-9. Al encuentro también asistieron representantes de la Generalitat de Catalunya, del Conseil Général de l'Ariège y del Govern d'Andorra. Por el contrario, destaca la ausencia de los municipios de la Cerdanya francesa y de otros representantes de Pyrénées-Orientales: en 2008 el alcalde de Bourg-madame se negó rotundamente a dar su apoyo debido al conflicto entre ambas Cerdanyas por el agua del río Carol, como se expondrá más adelante. Aquel mismo año 2010 se pronunciaron también, des de Toulouse, el Consell General de Cambres de Comerç de Catalunya, la Chambre Régionale de Commerce et d'Industrie MidiPyrénées y la Cambra de Comerç, Indústria i Serveis d'Andorra.

En ambos encuentros se apostó por el fortalecimiento y mejora de la infraestructura, pero, y a diferencia de las anteriores ocasiones, se quiere plantear el eje BarcelonaToulouse más allá de su condición viaria y de las relaciones comerciales, para apostar también por el fortalecimiento de las relaciones culturales, sociales y educativas, aunque sin detallar cómo se vincularían con la construcción de la autovía o por medio de cuáles estrategias. En relación a la competitividad, se argumentaba que la E-09 podría servir para disminuir la intensidad de tráfico, especialmente de camiones, en la auto- 
pista Girona-Perpignan-Narbonne, argumento visto con reticencia por los medios de Pyrénées-Orientales, cuyo Conseil Général apostaba por mejorar las conexiones por el litoral mediterráneo (la ruta europea E-15). Las demandas fueron despachadas por los gobiernos francés y catalán, argumentando los altos costes económicos y ecológicos que supondrían las obras y además, en el caso francés, el Gobierno optaba por priorizar el enlace Toulouse-Castres. Además del ejercicio de presión, municipios y cámaras de comercio se habían propuesto establecer una asociación estable, que no llegó a tomar forma, paradójicamente, ante las negativas gubernamentales.

\subsubsection{El ferrocarril transpirenaico Ripoll-Puigcerdà-Ax-les-Thermes}

A lo largo de la segunda mitad del siglo XIX los gobiernos español y francés contemplaron la posibilidad de construir varias líneas ferroviarias transpirenaicas, entre las cuales una que cruzara la cordillera por la Cerdanya. A pesar de ello solo se materializaron dos por los extremos del macizo, por Irún y Portbou, mientras que el paso por el interior no se resolvió hasta inicios del siglo XX, con la firma del Convenio internacional sobre la construcción de los ferrocarriles transpirenaicos de 1904 y su ratificación por parte de Francia y de España en 1906 y 1907 respectivamente. Se acordaron tres líneas, una de las cuales uniría Ripoll y Ax-les-Thermes por la Cerdanya, que contaría con dos estaciones internacionales, una en Puigcerdà y otra en Latour-deCarol, punto donde se conectarían las vías española y francesa (Baqué y Carral, 1999; Clara, 2004). La construcción sufrió retrasos considerables por razones de procedimiento, viabilidad económica, dificultades del terreno y otras complicaciones no previstas. Con todo, las obras no empezaron en Ripoll hasta fines de 1911 y no se alcanzó Puigcerdà hasta 1922. En Ax les obras se iniciaron un poco antes, en 1909, pero se vieron retrasadas debido a la Primera Guerra Mundial. El enlace entre ambas líneas en Latour-de-Carol se produjo finalmente en 1929.

Un avance de las obras que se percibía como demasiado lento hizo crecer la incertidumbre y la inquietud entre promotores, empresarios y políticos de las comarcas catalanas del Ripollès y la Cerdanya, y de los departamentos de Ariège y PyrénéesOrientales; incluso en algún momento se llegó a temer que el proyecto se abortara. Frente a esta situación se estableció una intensa colaboración transfronteriza con el objetivo de asegurar y agilizar la construcción del ferrocarril, cuyas acciones deben situarse en un contexto de gran interés por el ferrocarril entre la clase alta del Pirineo. Entre 1904 y 1906 se celebraron algunas asambleas transfronterizas a las que asistían varias personalidades de ambos lados de la frontera (representantes de los gobiernos locales, de empresas y bancos, y de los medios de comunicación locales, entre otros). Las citas se llevaron a cabo alternativamente en Puigcerdà y Ax-les-Thermes. En estos encuentros se daba cuenta de los avances y de las gestiones hechas para acelerar las obras. Los resultados insuficientes y el continuo desinterés mostrado por los gobiernos estatales, sobre todo el español, obligaron a un aumento constante de los esfuerzos. 
Por otra parte, en la primera asamblea se creó la Comisión Gestora Internacional del Transpirenaico Ax-Puigcerdà-Ripoll, que se estructuró en tres subcomisiones de seis representantes cada una: una para la Cerdanya española y el Ripollès, otra para la Cerdanya francesa y Ariège y una tercera en Barcelona. Su objetivo era doble: por un lado, estudiar los beneficios derivados del ferrocarril y, del otro, presionar los gobiernos estatales para que, en primer lugar, ratificaran cuanto antes el Convenio y, después, aceleraran las obras. De las varias acciones desarrolladas, dos son ilustrativas. En primer lugar, la subcomisión de Barcelona elaboró un informe sobre las ventajas económicas que se podían derivar de la línea. El estudio, Memoria acerca del trazado y ventajas que proporciona su construcción (1905), se envió al presidente del Consejo de Ministros. Se detallaban varios aspectos técnicos (las longitudes de los tramos español y francés, la petición de la doble vía o los costes de la construcción). También se indicaba los beneficios derivados a nivel local y regional y, con una clara intencionalidad, a nivel estatal y supraestatal: para Francia podía representar una línea directa entre París y Argel y para España, la vía más corta para unir el puerto de Barcelona con Toulouse, Bordeaux, París y los puertos atlánticos de la Rochelle y le Havre. La subcomisión francesa elaboró un informe similar, en el cual, y a diferencia del anterior, se reconocía un impacto territorial restringido, pero se consideraba que a la larga favorecería la penetración económica, el comercio entre las áreas fronterizas y el establecimiento de relaciones amistosas entre ambos países. En relación al ejercicio de presión, en segundo lugar, se puede destacar una acción que causó un gran impacto político y geopolítico: en 1906 la Comisión ofreció en territorio español una fiesta en honor a Téophile Delcassé, diputado por Foix y ex-ministro d'Affaires étrangères, y Emmanuel Brousse, consejero en el Conseil Général de PyrénéesOrientales, por sus gestiones a favor del tren, que en algunos medios españoles no fue bien acogida. Con la llegada del tren a la Cerdanya por la collada de Toses, a partir de 1919, la Comisión prácticamente cesó sus actividades y se limitó a participar, y a veces organizar, las sucesivas inauguraciones de los tramos y de las estaciones. Estas celebraciones se convirtieron, en buena medida, en fiestas de amistad transpirenaica, tal y como las describe Rafael Gay de Montellà (1964), miembro de la Comisión.

En las décadas posteriores se puso de manifiesto que el ferrocarril no suponía las ventajas competitivas ni beneficios que se habían previsto, puesto que el transporte de pasajeros y mercancías era deficitario, agravado por la rápida preferencia que se impuso por el transporte por carretera. Asimismo, progresivamente acumuló importantes deficiencias por falta de inversión. A mediados de los años 1980, en vísperas del ingreso de España en la Comunidad Económica Europea, RENFE previó la supresión del servicio Barcelona-Puigcerdà. En este contexto, en 1984 la Comisión Transpirenaica de Poderes Locales reclamaba la modernización de la totalidad de su itinerario (BarcelonaToulouse). Asimismo solicitó al Ministerio de Fomento que se estudiara la posibilidad de reconvertir el tramo entre la frontera y Barcelona al ancho de vía europeo. Sin embargo, como ya se ha expuesto en el epígrafe anterior, dicha asociación pronto relegó esta infraestructura a un segundo plano en detrimento de la E-09. En esas mismas fechas, en 1986, se creó la Asociación Transpirenaica Toulouse-Barcelona (ATTB), enti- 
dad transfronteriza promovida por la Chambre de Commerce et d'Industrie de Toulouse a la que se unieron las cámaras de comercio de Barcelona, Girona y Ariège, además de algunos gobiernos locales, entre los cuales los ayuntamientos de Barcelona, Ripoll, Foix y Toulouse, para la reivindicación de mejoras en la línea ferroviaria. Sobre una base argumentativa comercial y, en menor medida, social se encargó la redacción del Informe de l'eix ferroviari Barcelona-Paris: Ripoll-Puigcerdà-Foix (1986), donde se detallaban algunas propuestas. Se sugería la adaptación al ancho de vía europeo, la construcción de tres grandes plataformas logísticas para el transporte de mercancías (en Vic, Latourde-Carol i otra en Toulouse o Limoges) y la circulación de trenes Talgo, entre otras. Sin embargo, en el argumentario de la Asociación Transpirenaica no se tenían en cuenta las desventajas competitivas en relación al transporte por carretera.

Las peticiones de una y otra asociación, especialmente las relativas a los tramos estrictamente pirenaicos, no se incluyeron en los planes de los gobiernos francés y español arguyendo los altos costes y la baja rentabilidad de la línea. Con esta negativa, los miembros institucionales de ATTB fueron abandonando progresivamente la asociación y, desde mediados de los años 1990, se trata puramente de una entidad cívica, con triple sede (Ripoll, Andorra la Vella y Foix), y que ha contado con la colaboración de algunas empresas y entes locales, en especial el Consell Comarcal del Ripollès. A instancias de esta asociación, en 2004 se formó el Foment Turístic del Pirineu, patronato que promueve un tren turístico en el tramo entre Ripoll y Latour-de-Carol, el "Tren Verd", a semejanza del "Train Jaune", uno de los principales recursos turísticos del departamento de Pyrénées-Orientales.

Por último, durante la primera década del siglo XXI se sucedieron constantemente reclamaciones de mejora del tramo Barcelona-Puigcerdà (SCOT, 2004 y 2007). En este contexto, en 2009 varios representantes públicos locales y empresariales, con el apoyo de la Generalitat de Catalunya y la Universitat de Vic, relanzaron la reivindicación del ancho europeo. En esta ocasión los argumentos de tipo comercial (transporte de mercancías) se situaban ya en segundo término, puesto que les era evidente que no se podía competir con el transporte por carretera. Por el contrario, se esgrimían razones de tipo social relativas al uso del transporte colectivo (movilidad laboral con destino al área de Vic y la región metropolitana de Barcelona, y movilidad de personas sin acceso al transporte privado) y de desarrollo turístico. A diferencia de las anteriores ocasiones, en esta no se involucraron las autoridades locales y regionales de Pyrénées-Orientales y Midi-Pyrénées, argumentando que el número de pasajeros (reales y potenciales) entre Barcelona y Toulouse era ínfimo.

\subsection{Equipamientos sanitarios: el Hospital de Cerdanya}

Los flujos sanitarios transfronterizos en la Cerdanya han sido relativamente débiles a lo largo de la segunda mitad del siglo XX: solo unos pocos pacientes del lado fran- 
cés acudían al hospital de Puigcerdà (Moncusí, 2005) e, igualmente, algunos más del lado español asistían a los centros de salud de la Cerdanya francesa, aunque exclusivamente vinculados al turismo de salud y termal (Llugany, 2005). La Securité Sociale francesa y el Servei Català de Salut han firmado tres convenios (en 1996, 2001 y 2006) relativos a la asistencia médica de urgencias de pacientes franceses en Puigcerdà, lo que ha facilitado la atención e incrementado los flujos. A pesar de la baja movilidad sanitaria, el contexto sanitario en ambos lados de la frontera, aunque diferente, y amplificado por la importante reestructuración que llevaron a cabo los gobiernos de Catalunya y Francia en los años 1980 y 1990, confluyó en un interés compartido por la asistencia transfronteriza (Mancebo, 1999a; Séchet y Keerle, 2009). En el lado español, el hospital de Puigcerdà presentaba varias deficiencias, debidas sobre todo a la antigüedad del edificio (del siglo XII) y a la capacidad limitada de poder ampliarlo y, con ello, aumentar la dotación y servicios médicos; por el contrario, para recibir la mayor parte de los servicios especializados la población debía trasladarse a Manresa o Barcelona. En esta tesitura, la Generalitat de Catalunya determinó ampliar el hospital de la Seu d'Urgell y derivar allí los pacientes de la Cerdanya. En el lado francés, por otra parte, no existía hospital alguno, sino que los centros de referencia eran Prades y Perpignan, a la par que la reordenación del sector sanitario comportó la clausura de buena parte de los establecimientos privados que había en la Cerdanya.

Frente a esta situación, ya desde fines de los años 1970, se propusieron algunas soluciones de carácter transfronterizo, que se resumen en compartir un hospital al que pudiera acudir la población de ambos lados de la frontera, además de la población turista y de segunda residencia que se traslada en los periodos vacacionales y fines de semana. La primera propuesta en esta dirección se formuló en 1978 desde Toulouse, aunque tuvo una escasa recepción entre los agentes locales, ni mucho menos regionales y estatales. No fue hasta fines de los años 1980 que los gobiernos locales, articulados en la Asociación de Municipios de la Cerdanya (AMC), acogieron la idea. Mediante el apoyo de la Eurorregión Catalunya-Languedoc-Roussillon-Midi-Pyrénées, en 1991 los gobiernos de Catalunya y Languedoc-Roussillon firmaron un convenio para la realización de un estudio sobre un posible hospital transfronterizo. El informe, elaborado en 1994 por el Ordre des Médecins des Pyrénées-Orientales, evaluaba la posibilidad de asistir al conjunto de la población en el hospital de Puigcerdà, siguiendo el modelo utilizado en otros centros fronterizos de Europa (como en el Centre hospitalier La Palmosa, en Menton, en la frontera franco-italiana), o bien en uno de nueva construcción. Sin embargo, poco después, cambió el color político del Conseil Régional de Languedoc-Roussillon; al nuevo gobierno no le interesó el proyecto y finalmente se abortó.

Por tercera ocasión, una década después y una vez ya se aplicaba el convenio transfronterizo sanitario de 1996, resurgió el interés por un hospital transfronterizo. De nuevo, los ayuntamientos de ambos lados de la frontera fueron los primeros en reivindicarlo, apostando por la construcción de un nuevo equipamiento, que sustituyera el antiguo de Puigcerdà. El nuevo debería contar con mayor capacidad para pacientes, mayor y mejor aten- 
ción y más servicios médicos; asimismo, debería contar con personal español y francés y trilingüe (catalán, castellano y francés) para poder asistir a la población de ambos lados de la frontera. Además de los argumentos sanitarios, se señalaba que su existencia podría generar efectos complementarios, como la fijación de la población (tanto de la población mayor, que tiende a migrar hacia las ciudades donde cuenta con los servicios que requiere, y joven), el soporte al desarrollo turístico y el refuerzo de la economía.

La propuesta se elevó a los representantes políticos y administraciones correspondientes, y contó de inmediato con el apoyo entusiasta de algunos cargos de PyrénéesOrientales, tales como Christian Bourquin, presidente del Conseil Général y, sorprendentemente, François Calvet, que años antes se había opuesto rotundamente. Igualmente tuvo una buena acogida en los medios de comunicación locales y regionales de ambos lados de la frontera. En el marco de las negociaciones del nuevo convenio firmado en 2001, las administraciones sanitarias retomaron las conclusiones del informe de 1994. Se acordó realizar un estudio de viabilidad (jurídica, económica, compatibilidad de los sistemas sanitarios, etc.), al que se sumaron los gobiernos regionales de ambos lados (el Conseil Général des Pyrénées-Orientales, el Conseil Régional de Languedoc-Roussillon y Generalitat de Catalunya), además de las administraciones sanitarias (Agence Régionale de Santé Languedoc-Roussillon, Departament de Salut, Servei Català de la Salut, Ministerio de Sanidad y Consumo, y Ministère de la Santé). Finalmente en 2003 se firmó el acuerdo de creación del nuevo hospital, que empezó a construirse en 2009 y que se prevé entre en funcionamiento en 2014. Durante este periodo se constituyó su órgano gestor, la AECT Hospital de Cerdanya (AECT-HC), integrado por las administraciones sanitarias apuntadas y, en representación de los gobiernos locales, el Ayuntamiento de Puigcerdà y el Consell Comarcal de la Cerdanya. Aceptada la propuesta por las administraciones superiores, los gobiernos locales sólo intervinieron puntualmente en el proceso. Participaron, por ejemplo, en la elección de la ubicación del nuevo equipamiento. Inicialmente se apostaba por Bourg-Madame o Ur, en Francia, opciones que contaron con el apoyo de las respectivas alcaldías, aunque finalmente Puigcerdà se posicionó como mejor opción, después que el Ayuntamiento cediera los terrenos donde se ubica, el Pla de Rigolisa, a unos $100 \mathrm{~m}$ de la frontera. Para esta ciudad se trataba de consolidar y densificar urbanísticamente el sector norte del municipio, actualmente una zona agrícola fragmentada por áreas residenciales de edificación aislada. Sin embargo la crisis del sector de la construcción e inmobiliario, que en la comarca se empezó a detectar a principios de 2007, frenó la urbanización y la construcción.

Por último, debe indicarse que se trata de una experiencia innovadora en Europa, en tanto que constituye el primer hospital concebido atendiendo a la dimensión transfronteriza y cuya gestión es asumida por un organismo transfronterizo. Su puesta en funcionamiento plantea varios retos a nivel jurídico y laboral, cuya solución depende en ocasiones de la AECT-HC, otras de los niveles estatales y otras de la propia Unión Europea. Por otra parte, hasta que no entre en funcionamiento es difícil predecir cuáles serán realmente sus efectos complementarios a nivel territorial, aunque se pueden 
aventurar algunos cambios. En relación a la movilidad sanitaria se prevé, por un lado, que la afluencia de pacientes franceses sea en los primeros años escasa, aunque aumente progresivamente, como se ha demostrado en el caso de los convenios específicos de 1996 y 2001; y, del otro, que aumente rápidamente la afluencia de aquellos pacientes que hasta ahora se dirigen a la Seu d'Urgell y Manresa. En ambos casos, Puigcerdà refuerza su centralidad regional y transfronteriza, lo que podría inducir a ser receptora de otros tipos de movilidad (laboral, compras y residencial).

\subsection{Gestión del agua}

Los conflictos y la cooperación entorno al agua se explican en parte por la no concordancia entre la frontera interestatal y el límite de las cuencas hidrográficas. A pesar que la mayor parte del trazado de la frontera de los Pirineos coincide con el límite entre cuencas, en algunos sectores la frontera divide una misma cuenca, como la del Segre, tributario del Ebro, en su parte alta -el valle de la Cerdanya-. A esto se añade la pervivencia de derechos de uso y captación de aguas, cuyo origen es anterior a la demarcación fronteriza de 1659-60 y que desde entonces están reconocidos en los tratados hispano-franceses. En este apartado se exponen el conflicto fronterizo relativo al trasvase de agua a otras cuencas y la reivindicación de estaciones depuradoras de aguas residuales en los cursos fluviales antes de cruzar la frontera. El argumento básico que sostienen las alianzas transfronterizas es la pertenencia a una misma cuenca hidrográfica, aunque, como se mostrará, sólo prevalece cuando los intereses locales sean compartidos a ambos lados de la frontera; por el contrario, cuando entran en contradicción se impone la lógica estatista. El segundo caso permite observar una situación de asimetría competencial, ya que, en relación al tratamiento de aguas residuales, en Francia los municipios tienen una mayor capacidad de decisión y gestión. Este mismo ejemplo pone de manifiesto que esta competencia es difícil de asumir individualmente para los municipios pequeños, por lo que generalmente se transfiere a los établissements de coopération locale ${ }^{11}$, en concreto a los syndicats. Por todo ello, añadiendo la alta fragmentación y distribución de las competencias sobre la gestión del agua entre varios niveles administrativos y organismos de gestión de cuencas, Maury y Richard (2011) califican de muy difícil la gestión del agua en este contexto transfronterizo. Además de los niveles local, regional y estatal, este segundo caso también refleja la incorporación de un cuarto nivel, la UE, mediante el financiamiento de las estaciones depuradoras con fondos destinados a la cooperación transfronteriza. Contrariamente a una de las críticas habituales a los fondos INTERREG (Perkmann, 2007), este caso ejemplifica una contribución a la resolución de problemáticas transfronterizas.

11. Los établissements de coopération locale (ECPL) equivalen a las mancomunidades y consorcios. 


\subsubsection{Defensa de las aguas de la cuenca alta del Segre}

La posibilidad de trasvasar aguas de la cuenca alta del Segre a cuencas vecinas, la del Ariège y la del Llobregat, ha sido bastante regular en los últimos cien años. En primer lugar debe hacerse referencia al trasvase de las aguas del lago Lanoux (Gil, 1992; Oliveras, 2012), en la cabecera del río Carol (en el departamento de Pyrénées-Orientales), el principal tributario del Segre, que en sus inicios estuvo directamente relacionado con la construcción del ferrocarril transpirenaico, a la par que ambas cuestiones confluyeron en algunas ocasiones. En 1906 el Conseil Général des Pyrénées-Orientales autorizó el uso de sus aguas para la construcción del ferrocarril y, en base a aquella autorización, en 1917 el Conseil Général de l'Ariège y la Compagnie de Chemins du fer du Midi proyectaron su aprovechamiento hidroeléctrico. El proyecto consistía en la represa y recrecimiento del lago y el trasvase de sus aguas al Ariège, en la cuenca del Garona. A pesar que el lago está ubicado en territorio francés, el proyecto desembocó en un conflicto fronterizo entre España y Francia que se prolongó durante cuarenta años. Los gobiernos locales de la Cerdanya, tanta la española como la francesa, y el gobierno español entendían que el trasvase suponía un incumplimiento del Tratado de Límites de 1866 entre ambos estados y del acuerdo posterior sobre las aguas del Carol para el canal de riego transfronterizo (el llamado canal o acequia de Puigcerdà). Después de años de negociaciones infructuosas, proyectos alternativos (1921, 1927, 1949, 1951, 1953 y 1955) y boicots (como la suspensión de las obras del tren transpirenaico), en 1956 se acordó someter la cuestión a arbitraje internacional. El tribunal, reunido en Ginebra y presidido por el rey de Suecia Gustaf VI Adolf, concluyó que el proyecto no era contrario a los tratados. Con esta resolución se rubricó en 1958 el Acuerdo bispano-francés sobre el aprovechamiento de las aguas del lago Lanoux (modificado en 1970), por el que Francia (en concreto la empresa Électricté de France, EDF) puede trasvasar las aguas al Ariège, aunque debe asegurar a España un caudal mínimo para el Carol mediante el trasvase de agua de la cabecera del Ariège, situado en el límite fronterizo con Andorra.

En el mismo momento en que los agentes territoriales de la Cerdanya en particular, y de las provincias de Lleida y Girona y del departamento de Pyrénées Orientales en general, tuvieron conocimiento del proyecto en 1917, celebraron reuniones de urgencia en Perpignan, Puigcerdà y Barcelona para analizarlo. Poco después se convocaron un par de asambleas transfronterizas, la primera en Bourg-madame y la segunda en Puigcerdà, presididas por diputados y alcaldes de ambos lados de la frontera. El rechazo fue unánime, aunque varios representantes de la Cerdanya francesa estaban dispuestos a aceptar un trasvase limitado. La negativa se argumentaba con base a las "leyes naturales" de los cursos fluviales y al Tratado de Limites, al mismo tiempo que se señalaba que el desarrollo agropecuario, industrial e, incluso, turístico de la comarca y, por extensión, de la cuenca del Segre dependían de las aguas del Carol (puesto que el caudal del Segre en su cuenca alta procede mayoritariamente de este). En la segunda asamblea se creó también un grupo permanente de trabajo y seguimiento, la Comisión Técnica Diplomática sobre las aguas de Lanoux (popularmente conocida como Comi- 
sión pro-Carol). Se le encargó el estudio de los derechos sobre las aguas y se la dotó con la capacidad de llevar a cabo las gestiones necesarias, entre las cuales hacer intervenir el Gobierno español a favor de la Cerdanya, incluida la francesa. El desarrollo de sus actividades se reflejó, por un lado, en la elaboración y publicación de dos informes (uno económico y otro jurídico) y, del otro, con conversaciones con la Mancomunidad de Cataluña, los ministerios de Fomento y de Estado y con el presidente del Gobierno. Los trabajos resultaron fructíferos, en tanto que el gobierno español procedió a negociar, basándose en los estudios elaborados por la Comisión, con el francés, que accedió a paralizar el proyecto.

A inicios de 1921, sin embargo, Francia reactivó su interés, e inmediatamente el Ayuntamiento de Puigcerdà procedió a hacer lo mismo con la Comisión. El procedimiento de este grupo de trabajo transfronterizo fue el mismo que años antes: después de elaborar un nuevo estudio, complementario a los anteriores, y de reemprender las conversaciones con las diputaciones provinciales y el gobierno español, este último negoció de nuevo con el francés. En esta ocasión Francia se comprometió a no iniciar las obras hasta que no se resolviera el litigio. El conflicto apareció de nuevo en 1927 y 1952, aunque en estas ocasiones la movilización de los agentes locales ya no fue tan intensa, sino que quedó reducida a la acción particular del Ayuntamiento de Puigcerdà y algún otro, las comunidades de regantes y algunas empresas, en especial la Compañía Barcelonesa de Electricidad, Riegos y Fuerza del Ebro, S.A. ("La Canadenca"); por el contrario, la iniciativa la tomaron la Diputación provincial de Lleida, la Confederación Hidrográfica del Ebro y el gobierno del estado, hasta el desenlace conocido.

A diferencia del asunto de las aguas del Lanoux, la última propuesta de trasvase, del Segre al Llobregat en 2008, no generó un movimiento transfronterizo de oposición. Cómo solución a la sequía que padeció la región metropolitana de Barcelona en 20062008 se proyectó abastecerla con agua del Segre, aprovechando la galería de servicio del túnel del Cadí (Aldomà, 2012). Frente a esta propuesta, la reacción en la Cerdanya española y en el conjunto de la cuenca fue de rechazo, por la forma cómo se planteó y porqué los derechos de explotación, tanto para la agricultura como para el consumo doméstico, se veían amenazados. Primero el Ayuntamiento de Bellver y después el Consell Comarcal y el resto de ayuntamientos de la Cerdanya española aprobaron una moción en contra. Después de aquella acción prácticamente no hubo tiempo para más, debido a que las reacciones políticas a nivel regional y estatal y, sobre todo, las precipitaciones que pusieron fin a la sequía abortaron el proyecto. Por su parte, los gobiernos locales de la Cerdanya francesa mostraron una total indiferencia hacia la propuesta y una nula solidaridad. Si bien es cierto que el trasvase no afectaba para nada aguas arriba, su omisión también se debió al conflicto que en aquel mismo periodo enfrentaba ambas Cerdanyas por los aguas del Carol desviadas hacia el canal de Puigcerdà (Oliveras, 2013). De acuerdo a los derechos históricos garantizados por los tratados fronterizos, Puigcerdà puede captar un máximo de agua de aquel río en suelo francés, aunque independientemente de cuál sea su caudal. Las autoridades francesas representa- 
das en la Comisión Internacional de Administración de dicha acequia así como otras autoridades locales de la comarca reclamaban que, en un contexto de sequía, Puigcerdà debería captar una menor cantidad, por razones éticas, ambientales y de equidad. La negativa por parte de la Cerdanya española influyó directamente en la decisión de los ayuntamientos del lado francés de no sumarse a la oposición al trasvase al Llobregat y, en otro ámbito, a la reivindicación relativa al eje E-09.

En este caso aparece doblemente contradictoria la posición de los gobiernos locales españoles. Primero, a la vez que rechazaban el trasvase hacia Barcelona, no renunciaban a su captación aguas arriba. Segundo, para un caso reclamaban el apoyo de los gobiernos locales franceses con base a una lógica transfronteriza, mientras que para el otro hacían uso de la división fronteriza. Como en ningún otro de los casos analizados, aquí se refleja claramente la prevalencia de los intereses particulares de cada lado por encima de un interés común transfronterizo, y que en función de ellos se puede recurrir a argumentos basados en la adscripción político-administrativa o la pertenencia a un espacio transfronterizo (como es la cuenca hidrográfica).

\subsubsection{Las depuradoras de Puigcerdà, Latour-de-Carol-Enveig y el Pas de la Casa}

Las poblaciones ribereñas a los ríos Segre y Carol históricamente habían vertido sus aguas residuales sin previo tratamiento. Sin embargo el crecimiento demográfico, urbano y turístico de los principales núcleos de población, muy especialmente a partir de la apertura del túnel del Cadí, hacían urgente su depuración. En este contexto, a principios de la década de 1970 los ayuntamientos de la Cerdanya española, en especial Puigcerdà y Llívia, y la Comisión Internacional de Administración del canal de Puigcerdà, reclamaban que se trataran las aguas río arriba, antes de cruzar la frontera. A la petición se sumaron algunos municipios franceses, como Bourg-madame que, por su ubicación, también se veían afectados. La propuesta se elevó en 1972 a la Comisión mixta hispano-francesa de aguas fronterizas (dependiente de la Comisión Internacional de los Pirineos), que procedió a estudiar la cuestión. Con bastante retraso, en 1978, se concluyó que era necesario construir una planta de tratamiento en el Segre que diera servicio a aquellas tres localidades. Sin embargo, los cambios políticos de aquel momento y la falta de voluntad a nivel estatal impidieron su materialización.

La creciente presión urbanística y turística de los años 1980 no hacía más que aumentar su necesidad. Como en otros casos ya mostrados, en 1989 y en el marco que ofrecía la AMC, varios municipios de ambos lados de la frontera, el Consell Comarcal de la Cerdanya y el Syndicat d'Eau Potable et d'Assainissement de la Soulane acordaron afrontar los problemas de saneamiento de las aguas del Segre y el Carol (incluidas las procedentes del Pas de la Casa, en Andorra, que, como consecuencia del Acuerdo del lago Lanoux, estaban siendo transvasadas al Carol). La propuesta se trasladó a las autoridades regio- 
nales con la finalidad de que evaluaran la calidad de las aguas y la necesidad de equipamientos para su tratamiento. La Junta de Sanejament de Catalunya (JSC, la actual Agència Catalana de l'Aigua), la Agence de l'Eau Rhône-Méditerranée-Corse y el Conseil Régional de Languedoc-Roussillon asumieron el encargo, que se llevó a cabo durante 1992 y 1993 con financiación del programa INTERREG I. Finalmente en 1994 se inició la construcción de la Estación Depuradora de Aguas Residuales (EDAR) de Puigcerdà (que entró en funcionamiento al cabo de un año), situada en el lado español junto al río Segre pocos metros después de cruzar la frontera, y de una planta potabilizadora en 1996, también en Puigcerdà, situada junto al canal que aporta aguas del Carol a la ciudad.

Por otra parte, en 1995 la JSC y el Syndicat Mixte de Gestion de la Station Internationale de Puigcerdà, établissement de coopération locale que representa los intereses de los municipios franceses, negociaron la conexión de los colectores de las poblaciones de Angoustrine-Villeneuve-des-Escaldes, Bourg-Madame, Dorres y Ur a la depuradora, que se hizo efectiva en 1996 (posteriormente el convenio se amplió a otras poblaciones ${ }^{12}$ ). Las obras contaron con el apoyo financiero del programa INTERREG II. Durante las negociaciones, la Generalitat de Catalunya exigió al Gobierno francés el saneamiento del río Carol y que este presionara al Gobierno de Andorra para que hiciera lo mismo con las aguas del Pas de la Casa. El Gobierno andorrano accedió y en el Pla de sanejament de les aigües d'Andorra de 1996 incluyó la construcción de un depuradora y un colector en el Pas de la Casa, que están en marcha desde 1998. Por su parte, el Syndicat Intercommunal à Vocation Multiple de la vallée du Carol, con el apoyo de los gobiernos regional y estatal y del programa INTERREG II, además del apoyo simbólico del Ayuntamiento de Puigcerdà, desarrolló también un proyecto relativo a las aguas de este curso. El proyecto, iniciado en 2003 , se centraba en la descontaminación y en el tratamiento de las aguas residuales, y finalizó en 2009 cuando se puso en funcionamiento la depuradora de Latour de Carol-Enveig, situada unos pocos metros antes de cruzar la frontera.

\section{Conclusiones}

Más allá de constatar que los agentes locales son claves en la construcción regional transfronteriza, afirmación ampliamente respaldada por las investigaciones realizadas hasta el momento, el presente estudio permite cubrir una de las lagunas sobre el proceso de construcción. Debe recordarse que la literatura académica relativa a esta cuestión se ha limitado, en lo que corresponde al tema aquí tratado, a la concertación

12. Actualmente están conectadas las redes de las siguientes poblaciones: Puigcerdà (Puigcerdà, Age y Vilallobent), Llívia (Llívia y Gorguja), en España; Angoustrine-Villeneuve-des-Escaldes, Bourg-Madame (BourgMadame, Caldagas y Onces), Dorres, Err, Estavar (Estavar y Bajande), Llo, Saillagouse (Saillagouse, Ro y Vedrignans), Sainte-Léocadie y Ur, en Francia. 
y realización de proyectos territoriales sobre los que los agentes locales poseen competencias. Los ejemplos expuestos permiten argumentar que dicho proceso no se restringe a la ejecución y realización de los proyectos, sino que resulta igualmente significativa su proposición o rechazo, en función del caso. Es por ello que se ha querido mostrar cuál es el rol de los agentes públicos locales fronterizos en la reivindicación a favor y en contra de proyectos relativos a ámbitos sobre los que no detentan las competencias administrativas, y cómo ello contribuye a la integración territorial del espacio transfronterizo.

En primer lugar, los casos analizados permiten argumentar que frente a estas situaciones se han creado alianzas transfronterizas (desde la celebración de reuniones y asambleas hasta la formación de comisiones y asociaciones) con el objetivo de abordar la cuestión, proponer y reivindicar nuevas infraestructuras, equipamientos o servicios pensados en y desde un contexto transfronterizo o interregional, dependiendo del caso, u oponerse a otros pensados en y desde niveles superiores, en contextos internos del territorio estatal. En este sentido se ha identificado el proceso seguido, lo que se muestra, de forma esquematizada, en la figura 5. La detección por parte de los agentes locales de un problema y/o necesidad relativo al espacio transfronterizo conduce a la elaboración de propuestas, que se elevan a su vez a los niveles administrativos correspondientes, ya sean regionales o estatales. Si bien es cierto que la iniciativa y peso principal ha correspondido a los gobiernos locales, se da también una destacable interacción entre estos y las empresas y/o las cámaras de comercio, como en el caso de la vía E-09, y también, aunque en menor medida, la sociedad civil, como en el caso del ferrocarril transpirenaico. En ocasiones se cuenta también con el apoyo o la intermediación de organismos de cooperación transfronterizos ya existentes de orden local o regional, como haya podido ser la Euroregión Catalunya-Languedoc-Roussillon-MidiPyrénées, e incluso estatal, como la Comisión Internacional de los Pirineos. Por último, de realizarse los proyectos existe la posibilidad de recibir apoyo de la UE, mediante el financiamiento específico para la cooperación transfronteriza, como en el caso de las estaciones depuradoras y el hospital.

La dimensión histórica que aporta el análisis de las reivindicaciones realizadas con anterioridad a la regulación jurídica de la cooperación transfronteriza, muestra que los procesos, tanto antes como después de la regulación, son similares. Las estrategias de los agentes locales cuando, teniendo la capacidad de cooperar a nivel transfronterizo, no poseen competencias en determinados ámbitos son prácticamente las mismas que cuando no tienen la capacidad formal de cooperar. La principal diferencia radica en el grado de involucración de los gobiernos locales: obviamente, por sus características, es mucho mayor en un contexto regulado, mientras que la incapacidad de cooperar condujo a los cargos públicos a actuar más a título individual, a la par que la sociedad civil y los agentes privados tuvieron un mayor peso. 


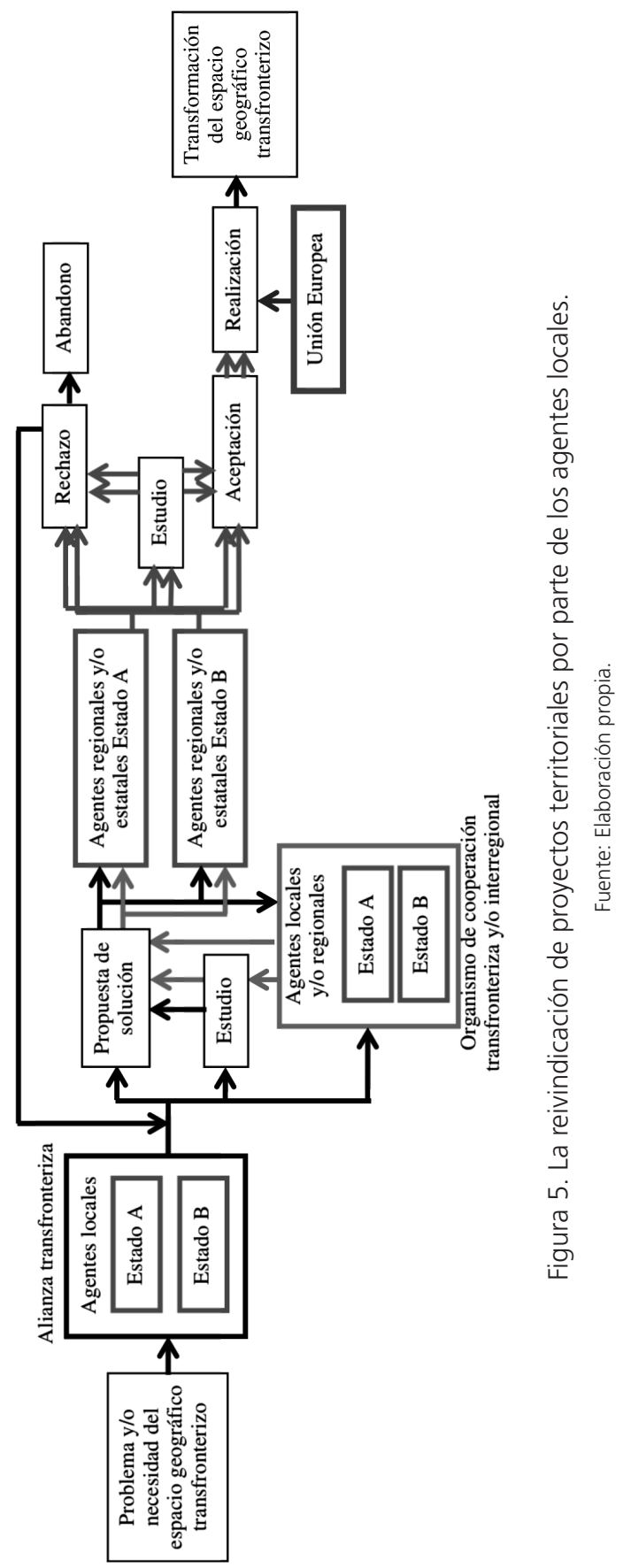


En segundo lugar, las reivindicaciones pueden ser o no aceptadas por los niveles superiores. Propuestas como la construcción de un hospital transfronterizo y de depuradoras fueron asumidas y realizadas, mientras que otras, como la conversión en autopista de la vía E-09 entre Bagà y Ax-les-Thermes, han sido, por el momento, rechazadas por las administraciones de ambos lados de la frontera. Independientemente de ello, la simple concertación de estrategias transfronterizas contribuye a la construcción regional del espacio transfronterizo, aunque sea a nivel institucional y simbólico. Sin desmerecer esta dimensión, la transformación del espacio geográfico se materializa mediante su realización. Los casos relativos a las infraestructuras de transporte no han tenido el impacto esperado, en parte por las altas expectativas generadas: en la escala local, han servido para integrar las áreas pirenaicas a las regiones metropolitanas de Barcelona y Toulouse, mientras que en la regional, las relaciones entre ambas se ha vehiculizado por otras vías. Por el contrario, la puesta en marcha de las depuradoras ha permitido la resolución de un problema local y transfronterizo y su gestión igualmente transfronteriza. Los servicios médicos y la movilidad que se espera que generen, pendientes de poder avaluar una vez haya entrado el hospital en funcionamiento, podría favorecer la cohesión de las dos Cerdanyas, así como favorecer otros aspectos, tales como la retención de la población y el incremento de las actividades económicas en Puigcerdà.

En tercer lugar, el grado de respuesta y las dificultades del proceso no se limitan solo a la posesión o no de las competencias, sino que intervienen otros factores. Primero, la complejidad que acarrea la distribución de aquéllas, muchas veces asimétrica, en cada uno de los países fronterizos. Segundo, no se puede asumir la prevalencia de intereses comunes a ambos lados de la frontera. Por el contrario, pueden ser muy frágiles y prevalecer, en cambio, los intereses particulares de cada lado, impidiendo así la concertación de aquellas alianzas. Como se ha podido ver, un conflicto local fronterizo, como el derivado de la captación de agua del río Carol en la Cerdanya francesa por parte de la española en el período de sequía de 2006-2008, tuvo como consecuencia la reivindicación por parte de la española de sus derechos, en detrimento de la francesa, y con base a una lógica estatal. Consiguientemente, los agentes de Pyrénées Orientales no participaron en la oposición al trasvase del Segre al Llobregat ni en la reivindicación de la ampliación de la E-09. Tercero, debe tenerse en cuenta el interés y prioridad de los proyectos en los diferentes niveles administrativos y escalas geográficas. En la toma de decisiones influyen, como en otras ocasiones, cuestiones políticas, ideológicas y de financiación. En los espacios fronterizos se añade además, primero, el déficit de inversión estatal por su carácter periférico, y segundo, la (in)capacidad de los niveles regionales y, sobre todo, estatales, y sin descartar los locales, de (re)dimensionar los espacios fronterizos en espacios transfronterizos. Se debería, por lo tanto, pasar de una concepción donde las regiones fronterizas equivalen a espacios periféricos a otra donde constituyen nexos de unión, y de una donde son "normalmente" asociados a un espacio político y metageográfico nacional/estatal a otra en la que son transversales a los espacios nacionales/estatales, es decir, transfronterizos y transnacionales. Como recalcó la ARFE en su momento, ello no responde a la voluntad de poner en 
cuestión el rol de los estados-nación, sino de dotar a los espacios fronterizos / periféricos -y por consiguiente, sus poblaciones, servicios, equipamientos e infraestructurasde las mismas oportunidades de desarrollo territorial que los espacios centrales, en este caso mediante la actuación transfronteriza.

Para terminar, en contextos con distribución competencial en diferentes niveles es recomendable la cooperación multinivel, pero como se desprende, esta práctica solo se da en contadas ocasiones. Esto también refleja, como consecuencia de lo anterior, la inexistencia de una estrategia territorial transfronteriza, no asumida por los estados y no siempre por los agentes regionales y locales, donde, además de la participación de todos los agentes territoriales, de todos los niveles, se considere la región transfronteriza en su globalidad. Como se ha podido observar, las actuaciones han sido aisladas, a pesar que los agentes territoriales son a menudo los mismos. El objetivo último de la construcción regional por medio de la cooperación multinivel y el diseño de una estrategia territorial transfronteriza, debe ser mejorar la gestión integral de los espacios (trans)fronterizos y la calidad de vida de sus poblaciones.

\section{Bibliografía}

Aldomà, I. (2012) La batalla per l'aigua. Una proposta per superar els desconcerts hidrics i garantir la gestió integral del seu cicle a Catalunya. Lleida, Pagès.

Arbaiza, J.K. (2006) "Proyectos de cooperación transfronteriza en el País Vasco: objetivos y realidad". Lurralde: Investigación y espacio, 29, p. 143-177.

Baqué, D. y Carral, C. (1999) "L'arribada del tren a Puigcerdà: el Transpirinenc Ripoll-Puigcerdà-Ax-les-Termes". En ASSOCIACIÓ D'ENGINYERS INDUSTRIALS DE CATALUNYA: Arqueologia de la Comunicació. Actes de les IV Jornades d'Arqueologia Industrial de Catalunya. Barcelona, Associació d'Enginyers Industrials de Catalunya, p. 323-352.

Breugnot, J. (2012) "La construction des espaces frontaliers européens: entre dynamisme et résistance". Alterstice. Revue Internationalle de la Recherche Interculterelle, 2 (1), p. 67-78.
Clara, J. (2004) El Transpirinenc català: Ripoll-Puigcerdà-La Tor de Querol. Barcelona, Rafael Dalmau.

Cohen, A., Raineau, L. y Sempere, J. (2011) "Balance comparativo de las luchas contra la línea de muy alta tensión entre Francia y España a uno y otro lado de la frontera". Arxius de Ciències Socials, 25, p. 33-36.

Durà, A. (2012) "La cooperació territorial transpirinenca en el context de l'Arc Mediterrani". Treballs de la Societat Catalana de Geografia, 74, p. 57-75.

Embid, A. y Fernández de Casadevante, C. (2008) Las Agrupaciones Europeas de Cooperación Territorial. Consideraciones desde el Derecho comunitario y el Derecho español. Madrid, Iustel.

Fernández de Casadevante, C. (1989) La frontière franco-espagnole et les relations de voisinage. Bayona, Harriet. 
Fernández de Casadevante, C. (1990) La cooperación transfronteriza en el Pirineo: su gestión por las comunidades autónomas. Oñati, Instituto Vasco de Administración Pública.

Fernández, N. y Peralta, E. (1994) "El papel de la Comunidad de Trabajo de los Pirineos y su evolución en el contexto europeo de cooperación transfronteriza territorial". Revista de instituciones europeas, 21 (2), p. 499-528.

Galan, S. (1994) "La macrorégion barcelonaise, un espace transfrontalier". Méditerranée, 79 , p. $61-66$

Gay de Montellà, R. (1964) La Cerdanya. Barcelona, Selecta.

Gil, M.T. (1992) "El despropòsit del Lanós". $R u$ faca, 120, p. 33-36.

Giménez, R. (2012) "Ideologia i geopolítica en la configuració del sistema de transports transpirinenc (1982-2011)". Treballs de la Societat Catalana de Geografia, 74.

Harguindéguy, J.B. (2007) La frontière en Europe, un territoire?: coopération transfrontalière franco-espagnole. París, Harmattan.

Hinfray, N. (2007) "Les processus de construction des territoires transfrontaliers en Europe: éléments d'analyse". Mosella, 32 (14), p. 79-95.

Llugany, J. (2005) "Médecine, tourisme et accueil médical en Cerdagne-Capcir". Ceretania. Quaderns d'Estudis Cerdans, 4, p. 235-248.

Marcou, G. (2006) El alcance y la naturaleza de las competencias de las entidades locales en los estados miembros del Consejo de Europa. Madrid, Ministerio de Administraciones Públicas.

Maury, C. y Richard, S. (2011) "La difficile gestion de l'eau en contexte transfrontalier: un exemple franco-espagnol". Articulo. Journal of Urban Research, 6.
Mancebo, F. (1999) La Cerdagne et ses frontières: conflits et identités transfrontalières. Perpinyà, El Trabucaire.

Morata, F. (1995) "L’Eurorégion et le réseau C6. L'émergence du suprarégionalisme en Europe du Sud?". Pôle Sud, 3, p. 117-127.

Moncusí, A. (2005) Fronteres, identitats nacionals i integració europea: el cas de la Cerdanya. Catarroja / València, Afers / Universitat de València.

Muñoz, X. (1995) Les polítiques europees de cooperació transfronterera. El context normatiu, institucional $i$ de finançament als Pirineus Orientals. Vilassar de Mar, OikosTau.

Navarro, M.D. (2010) "Les competències dels governs locals: una anàlisi comparativa $i$ debat sobre el futur del món local a Catalunya". Papers de Treball, 9/2010.

Oliveras, X. (2012): "La contribució de Rafael Gay de Montellà (1882-1969) a la construcció d'espais supraestatals i transestatals: el Mediterrani llatí i la Cerdanya". Ausa, 170, p. $867-886$.

Oliveras, X. (2013) "La cooperación transfronteriza en la Cerdanya (frontera EspañaFrancia)". Boletín de la Asociación de Geógrafos Españoles (AGE), 62, p. 25-48.

Oliveras, X., Durà, A. y Perkmann, M. (2010) "Las regiones transfronterizas: balance de la regionalización de la cooperación transfronteriza en Europa (1958-2007)". Documents d'Anàlisi Geogràfica, 56 (1), p. 21-40.

Paasi, A. (1996) Territories, Boundaries and Consciousness: The Changing Geographies of the Finnish-Russian Border. Chichester, Wiley.

Perkmann, M. (2003) "Cross-border regions in Europe. Significance and drivers of regional cross-border co-operation". European Urban and Regional Studies, 10 (2), p. 153-171. 
Prat, M. (1994) "Projecció internacional de l'eix del Llobregat. E-09". En BOLÒS, M. de. (coord.): L'eix del Llobregat i el túnel del Cadi 10 anys després. Barcelona, Túnel del Cadí, C.E.S.A., p. 258-277.

Ramírez, S. (2005) "Las Zonas de Integración Fronteriza (ZIF): avances y retrocesos". Aldea Mundo. Revista sobre fronteras e integración, 18, p. 7-19.

Red de Ciudades C-6 (1992) Un espacio permeable y solidario al sur de Europa. Libro blanco de la comunicaciones terrestres. Toulouse, Mairie de Toulouse.

Séchet, R. y Keerle, R. (2009) "Le projet d'hôpital commun transfrontalier de Puigcerdà: vers l'européinisation de la frontière en Cerdagne". Sud-ouest européen: revue géographique des Pyrénées et du Sud-Ouest, 28 , p. 65-76.

Sempere, J. (2011) "Un debate público frustrado: el conflicto de la línea eléctrica de 400.000 voltios en el nordeste de Cataluña". Arxius de Ciències Socials, 25, p. 21-32.

Schneider-Sliwa, R. (2008) "Enjeux et transformations des régions métropolitaines du sud du Rhin supérieur", Revue Géographique de l'Est, 48 (3-4).

Silván, L. (2008) "Relaciones transfronterizas en los Pirineos". En SILVÁN, L. (coord.): Fronteras y globalización. Europa-Latinoamérica. Zaragoza, Prensas Universitarias de Zaragoza, p. 163-182.
Societat Catalana d'Ordenació del Territori (2004) Anuari territorial de Catalunya 2003. Barcelona, Societat Catalana d'Ordenació del Territori (SCOT).

Societat Catalana d'Ordenació del Territori (2007) Anuari territorial de Catalunya 2006. Barcelona, Societat Catalana d'Ordenació del Territori.

Sohn, C. (2010) "El papel ambivalente de las fronteras en la construcción de las metrópolis transfronterizas en Europa. Los casos de Basilea, Ginebra y Luxemburgo". Documents d'Anàlisi Geogràfica, 56 (1), p. 167-184.

Tambou, O. (2000) "El tractat de Baiona: un èxit relatiu per al desenvolupament de la cooperació transfronterera en l'àmbit de la frontera francoespanyola". Autonomies. Revista Catalana de Dret Públic, 26, p. 41-96.

Trillo, J.M. y Lois, R. (2011) "La frontera como motivo de atracción: una breve mirada a las relaciones Galicia-Região Norte". Geopolitica(s), 2 (1), p. 109-134.

Verpeaux, M. y Rimbault, C. (2011) Les collectivités territoriales et la décentralisation. París, La Documentation française.

Vivas, J. (2004) La Cerdanya, una ciutat al tombant del mil-leni? Metamorfosi de l'espai, la identitat $i$ el paisatge cerdà. Tesis doctoral: Universitat Autònoma de Barcelona. 